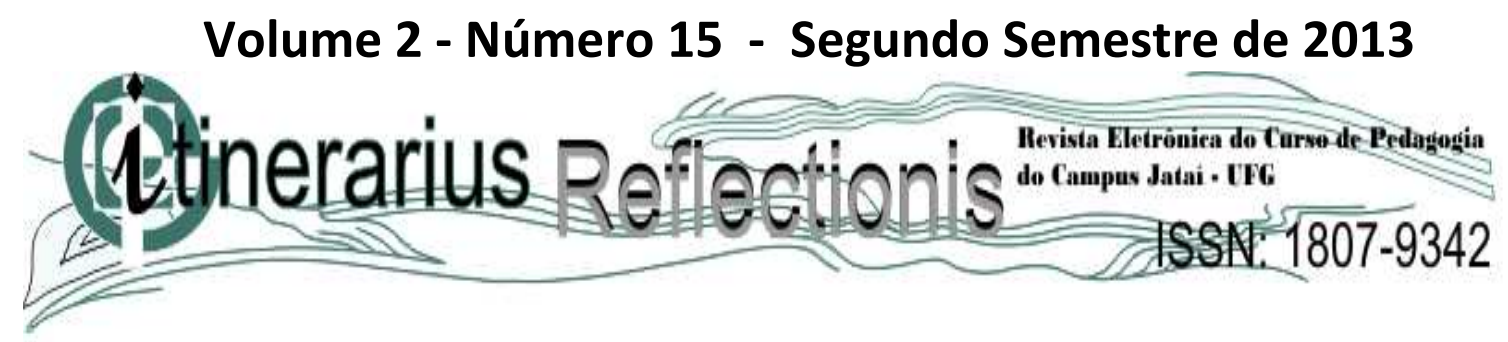

\title{
A EDUCAÇÃO RURAL NOS ANOS DE 1970: UM ESTUDO NO MUNICÍPIO DE MONTE ALEGRE DE MINAS, MG, BRASIL
}

\author{
Astrogildo Fernandes da Silva Júnior - Faculdade de Ciências Integradas do \\ Pontal/Universidade Federal de Uberlândia/Campus Ituiutaba; silvajunior_af@yahoo.com.br \\ Jovelina Macedo de Medeiros- Faculdade de Ciências Integradas do Pontal/Universidade \\ Federal de Uberlândia/Campus Ituiutaba; macedo@yahoo.com.br
}

\begin{abstract}
RESUMO O objetivo deste texto consistiu em apresentar o perfil da educação escolar no meio rural de Monte Alegre de Minas, estabelecendo relações com a educação do Brasil na década de 1970. Como metodologia, partiu-se do princípio de que toda pesquisa histórica requer trabalhar teoria e fontes, dessa forma, seguiram-se os seguintes passos: 1) a busca por uma bibliografia que tratasse do tema; 2) investigação da existência de fontes; essa etapa consistiu em uma pesquisa nos arquivos da Secretaria de Educação da cidade; 3) realização de uma pesquisa no site do Instituto Brasileiro de Geografia e Estatística - IBGE -, sobre o município de Monte Alegre de Minas e no site da Prefeitura da cidade, por fim, realizou-se uma entrevista com a Maria Aparecida da Silva, professora que atuou na Escola Municipal Olímpio dos Santos, nos anos de 1970. Concluiu-se que a educação rural que se efetivou no município de Monte Alegre de Minas foi marcada pela precarização tanto no que se refere ao espaço físico, como na formação de professores. Privilegiou o ensino das primeiras letras e a propagação do ideário da ditadura civil militar. Por meio do estudo do local, foi possível estabelecer relações com o global.
\end{abstract}

Palavras-chave: Educação rural; meio rural; Monte Alegre de Minas.

\section{RURAL EDUCATION IN THE 1970'S: A STUDY IN THE MUNICIPALITY OF MINE MONTE ALEGRE, MG, BRAZIL RURAL}

\begin{abstract}
The aim of this paper was to present the profile of school education in rural Monte Alegre de Minas, establishing relationships with the education of Brazil in the 1970s . The methodology began with the principle that all historical research requires working theory sources and thus followed the following steps : 1 ) the search for a bibliography that dealt with the topic , 2) investigate the existence of sources, such phase consisted of a search in the archives of the Department of Education of the city , 3) conducting a search on the website of
\end{abstract}


the Brazilian Institute of Geography and Statistics - IBGE - on the municipality of Monte Alegre de Minas and the site of city Hall, for order, held an interview with Maria Aparecida da Silva , a teacher who worked at the Municipal School Olympian dos Santos, in the 1970s . It was concluded that rural education that became effective in the municipality of Monte Alegre de Minas was marked by instability both in terms of physical space, as in teacher training which favored the teaching of the first letters and the spread of ideas of civil military dictatorship. Through the study site, it was possible to establish relations with the global. The aim of this paper was to present the profile of school education in rural Monte Alegre de Minas, establishing relationships with the education of Brazil in the 1970s. The methodology began with the principle that all historical research requires working theory sources and thus followed the following steps : 1 ) the search for a bibliography that dealt with the topic , 2) investigate the existence of sources, such phase consisted of a search in the archives of the Department of Education of the city , 3) conducting a search on the website of the Instituto Brasileiro de Geografia e Estatística Instituto Brasileiro de Geografia e Estatística - IBGE - on the municipality of Monte Alegre de Minas and the site of city Hall , for order, held an interview with Maria Aparecida da Silva, a teacher who worked at the Municipal School Olympian dos Santos, in the 1970s. It was concluded that rural education that became effective in the municipality of Monte Alegre de Minas was marked by instability both in terms of physical space, as in teacher training . Favored the teaching of the first letters and the spread of ideas of civil military dictatorship. Through the study site, it was possible to establish relations with the global.

Keywords: Rural Education; rural area; Monte Alegre de Minas

\section{Introdução}

A educação, no meio rural, não se constituiu historicamente em um espaço prioritário para uma ação planejada e institucionalizada no Estado brasileiro. Isso privou a população do campo, em especial, a classe trabalhadora, de ter acesso, de forma geral, às políticas e aos serviços públicos. Compartilhamos com Arroyo, Caldart e Molina (2004) da seguinte opinião: a escola, no meio rural, foi tratada como resíduo do sistema educacional brasileiro e, consequentemente, à população do campo foi negado o reconhecimento e a garantia do direito à educação básica.

Ao analisar as transformações no meio rural brasileiro, podemos verificar a transfiguração do rural sob a égide do capital. A partir da metade do século XX, ter uma agricultura modernizada significava a incorporação do pacote tecnológico da Revolução Verde $^{1}$. A agricultura se especializou e, dessa forma, é possível perceber as consequências no

1 A "Revolução Verde", característica do sistema capitalista brasileiro, na década de 1970, é considerada uma das responsáveis pelo êxodo rural. A concentração de terras é a causa de uma luta histórica no Brasil em defesa da Reforma Agrária. Com a modernização do campo, de forma conservadora, isto é, mantendo a mesma estrutura agrária, e expulsando ainda mais os trabalhadores do meio rural, a crise social e as possibilidade de confronto tendem a aumentar. 
que se refere à densidade demográfica. A partir de 1970, a população urbana brasileira passou por um processo de rápido crescimento e a população rural de esvaziamento.

Com base nessas reflexões, questionamos: como se efetivou a educação rural no municipio de Monte Alegre de Minas, MG, Brasil nos anos de 1970? Quais as aproximações e distanciamentos em relação à educação rural no Brasil nesse contexto? Dessa forma, nos limites deste texto, elegemos como objetivo apresentar o perfil da educação escolar no meio rural de Monte Alegre de Minas, estabelecendo relações com a educação do Brasil na década de 1970.

Inicialmente, registramos a perspectiva metodológica, em seguida, o cenário da investigação, ou seja, alguns aspectos do município de Monte Alegre de Minas, nos anos de 1970. Continuamos o texto enfatizando a educação que se efetivava no meio rural do município. Por fim, detivemos nosso olhar na Escola Municipal Rural Olímpio Vasconcelos e tecemos nossas considerações.

\section{A opção metodológica}

Em nossa investigação, buscamos apreender elementos da história cultural, principalmente no que se refere à articulação entre a micro-histórica com a macro-história. Essa corrente historiográfica preocupa-se não apenas com o pensamento das elites, mas também com as ideias e confrontos de ideias de todos os grupos sociais. O intuito dessa corrente é renovar a história política, procurando renovar os temas políticos, introduzindo a história das culturas políticas, dos regimes e sistemas de governo e das representações do poder. É caracterizada por uma perspectiva globalizante.

Segundo Duby (1998), a finalidade da história cultural é definir os modelos culturais que, em certos momentos, se impuseram a determinadas sociedades, dar conta do seu sucesso, enfim, perceber seu movimento, que, de forma lenta ou viva, branda ou brusca, acontece ao longo do tempo. O autor continua,

A tarefa consiste, pois, no inventário, numa determinada época, das bases de uma cultura. Quer dizer, em primeiro lugar, de um conjunto de signos e de símbolos - vocabulário, sintaxe, fórmulas e gestos rituais, figuras expressas pela música, pelo cerimonial ou pelas artes sólidas - que comandam os mecanismos mentais e pelos quais o espírito humano apreende o real, se situa em relação ao tempo, ao espaço e aos outros, e projeta no imaginário os seus desejos e as suas inquietações. A este nível de análise, em que podem ser utilmente postos em execução os métodos quantitativos, o historiador deve associar-se estreitamente aos dialectólogos 
e a todos aqueles que se dedicam ao estudo da semântica, da estilística, dos meios de percepção e de expressão (DUBY, 1998, p. 4005).

É necessário destacar que a cultura nunca é recebida uniformemente pelo conjunto de uma sociedade, que esta se decompõe em meios culturais distintos, muitas vezes, antagônicos. Dessa forma, de acordo com Duby (1998), a história cultural é, naturalmente, conduzida para o estudo da estratificação social e das estruturas de grupo. Assim, integra-se na história da sociedade, de que se alimenta e que, por sua vez, alimenta generosamente.

Nosso olhar sobre as escolas rurais de Monte Alegre, bem como a análise dos documentos procuraram relacionar o local com o global. Concordamos com Carlos (2007), ao afirmar que a globalização se materializa no lugar, aqui se lê, percebe e entende o mundo em suas múltiplas dimensões; numa perspectiva mais ampla, significa dizer que o lugar se vive e se realiza o cotidiano. Acreditamos que as características das escolas rurais do município pesquisado, no período do recorte da investigação, por um lado, dialoga com o que acontecia no meio brasileiro, por outro, tinha suas especificidades.

Iniciamos o processo da nossa investigação recorrendo a um levantamento bibliográfico. A tarefa da revisão bibliográfica não é listar todos os livros que forem importantes para o seu tema (isto poderá ser feito no final do projeto de pesquisa, em um item chamado "Bibliografia" ou "Referencias Bibliográficas"). O que se pede, na Revisão Bibliográfica, são comentários críticos sobre alguns itens da bibliografia existente que são considerados particularmente importantes, seja para neles se apoiar, seja para criticá-los. Posteriormente, realizamos um estudo nos arquivos da Secretaria de Educação da cidade. O terceiro passo foi a realização de uma pesquisa no site do Instituto Brasileiro de Geografia e Estatística - IBGE -, sobre o município de Monte Alegre de Minas, e no site da Prefeitura da cidade, por fim, realizamos uma entrevista com a Maria Aparecida da Silva (Lila), professora que atuou na Escola Municipal Olímpio dos Santos, nos anos de 1970.

Nosso trabalho no arquivo, ao longo de 2011, foi de uma média de 3 horas semanais, durante de seis meses. O primeiro passo se constituiu em verificar a existência dos tipos documentais, com a finalidade de conhecer os vestígios que esta documentação nos apresenta da cultura escolar rural de Monte Alegre de Minas. No segundo semestre de 2013, retornamos ao arquivo da Secretaria de Educação de Monte Alegre de Minas, com o intuito de retificar alguns dados coletados anteriormente, tais como: a relação idade/série de alunos, e o relato das atividades das datas comemorativas.

Nossa proposta da análise dos documentos leva em conta o que Le Goff (2008) nos ensina: o documento é um monumento e deve ser questionado, pois ele é fruto de sua 
sociedade. Para o autor, "O documento é monumento. Resultado das sociedades históricas para impor ao futuro-voluntariamente ou involuntariamente-determinada imagem de si próprias.” (LE GOFF, 2008, p. 538).

Se o documento é fruto de sua sociedade ele não está imune à relação de poder e aos jogos de interesses desta sociedade. Sendo assim, temos que analisá-los ponderando esta perspectiva. Le Goff (2008) chama a atenção para outro aspecto, o documento não pode ser tido como uma verdade total, e nem como uma mentira total. Portanto, em nossa pesquisa, analisamos as fontes questionando-as. Para o autor, o documento tem uma carga de imposição de imagem que a sociedade deseja incutir, mesmo que não seja voluntariamente. $O$ documento/monumento é "produto de um centro de poder".

A segunda etapa deste trabalho consistiu em realizar um levantamento do número de escolas localizadas no município de Monte Alegre de Minas no meio rural, investigando a quantidade de escolas e de alunos que fizeram parte do quadro escolar durante a década de 1970. Por fim, realizamos uma entrevista com a professora que atuou na escola investigada no contexto pesquisado.

Segundo Portelli (1997), a história oral, além de expressar a historicidade da experiência pessoal e o papel do indivíduo na história da sociedade, propicia ampliar os conhecimentos e as informações sobre um passado recente, por meio da versão de pessoas que o viveram. As pesquisas narrativas são histórias vividas e contadas, são uma forma de compreender a experiência. Pelas narrativas orais, cada pessoa recria suas diferentes versões sobre um mesmo período, valendo-se dos elementos de sua cultura, socialmente criados e compartilhados, conta não apenas o que fez, mas o que gostaria de ter feito, o que acreditava fazer e o que pensa que fez.

De acordo com Benjamin (1993), as narrativas permitem trazer a experiência de volta à história. Para o autor, o narrador é o homem que sabe dar conselhos. A narrativa tem sua dimensão utilitária, pode se constituir em um ensinamento moral ou em uma sugestão prática ou um provérbio, ou uma forma de vida. Não são verdades absolutas, não é uma rua de mão única. Reside aí a beleza do trabalho com narrativas. A narrativa conserva suas forças ao longo do tempo. Em síntese, nesta pesquisa, recorremos ao uso de fontes escritas e orais.

\section{O cenário da pesquisa: Monte Alegre de Minas}

O cenário é o lugar onde as pessoas vivem, dessa forma, marca suas identidades. Para compreender a educação que se efetivava em Monte Alegre de Minas, nos anos de 1970, 
consideramos fundamental conhecer um pouco deste tempo e lugar. Como pondera o poeta Fernando Pessoa, estar é ser.

Monte Alegre de Minas encontra-se situada na região do Triângulo Mineiro, faz divisa com os seguintes municípios: a oeste, os municípios de Ituiutaba e Canápolis, e noroeste Centralina, ao norte Tupaciguara; a leste o município de Uberlândia; ao sul o município de Monte Alegre estende sua fronteira com município do Prata.

Para pensarmos a educação rural em Monte Alegre de Minas, julgamos ser essencial refletir a respeito dos aspectos políticos, econômicos e sociais, pelos quais o Brasil passava ao longo dos anos de 1970. Esse período foi marcado, politicamente, pela ditadura civil militar. Em 31 de março de 1964, por meio de um golpe militar, o presidente João Goulart foi deposto, e os militares entraram em cena. Romperam radicalmente com as propostas de João Goulart e apresentaram outros planos para o desenvolvimento do Brasil. De acordo com Toledo (2004),

(...)1964 significou um golpe contra as reformas sociais e políticas; uma ação repressiva contra a politização das organizações dos trabalhadores (no campo e nas cidades); um golpe contra o amplo e rico debate ideológico e cultural que estava em curso no país. (p.64).

O autor destaca as características que marcaram o período da ditadura civil militar no Brasil, enfatizando a ausência da democracia e o poder da repressão. Segundo o autor, houve um abandono das propostas para de desenvolvimento para o país, e um silenciamento dos debates que se encontravam em voga antes do golpe.

Com a tomada do poder pelos militares, evidenciamos mudanças na política adotada pelo Estado Brasileiro. O projeto de desenvolvimento para o país, em 1964, foi abandonado, e os novos detentores do poder primaram por outras medidas, que iam ao encontro de uma pequena parcela da sociedade: a burguesia. O golpe não aconteceu apenas por interesse de alguns militares, para consumação de tal ação, eles obtiveram o apoio de alguns setores da sociedade que se encontravam descontentes. Ao chegarem ao poder, governaram em favor de poucos e mantiveram os privilégios da classe dominante. De acordo com Gonçalves Neto (1994),

(...) principalmente a partir de 1964 , terá por objetivo básico manter inalteradas as formas de acumulação dominantes na sociedade, compatibilizando interesses díspares de setores que lutam pelo controle dos principais fatores econômicos. Promove, portanto, a modernização de grande parte da agricultura, aumenta a produção e a produtividade sem, contudo, tocar nos padrões de acumulação. (P. 88-89). 
Segundo o autor, a partir do golpe civil militar de 1964, prevaleceram e reforçaram-se, na economia brasileira as formas de acumulação dominantes, fato que se evidenciou também no meio rural. De acordo com Silva Júnior (2007), verificou-se uma redução expressiva da população rural, em função do processo de urbanização. Este fenômeno "global" repercutiu no "local".

Segundo Bessa e Soares (2002), na região do Triângulo Mineiro, nos anos de 1970, a taxa de urbanização era de 57,5\% (629.987 habitantes), índice semelhante ao percentual brasileiro, que era de 56,8\%. A população de Monte Alegre de Minas cresceu 4,6\%, de 14.687 habitantes, em 1970, para $15.359 \mathrm{em} 1980$.

Em âmbito nacional, a política adotada pelo governo militar tinha como meta "modernizar" a sociedade brasileira da década de 1970. Para isso, foi proposto um pacote econômico que ficou conhecido como "Milagre Econômico". Conforme Earp e Luiz Prado (2003), o objetivo era proporcionar um desenvolvimento econômico semelhante ao dos países "desenvolvidos".

Em âmbito local, o desejo de transformação e obter mudanças em sua sociedade não foram diferentes. No arquivo digital da prefeitura de Monte Alegre de Minas, encontramos várias leis que assumiam este caráter de "modernização" do município. Em 1971, destacamos a lei $n^{\circ} 776$, a qual tratava 'de dinheiro para extensão elétrica; Lei $\mathrm{n}^{\circ} 792$ referente às obras de saneamento publico; $n^{\circ} 796$, construção de calçamento e meio fio; Lei $\mathrm{n}^{\circ}$ 804, para a autorização de construção de uma estação rodoviária; Lei 857 de 1972, que autorizava a venda de casas populares; Lei 880, em 1973, com a aprovação da linha de telégrafo; Lei 902, em 1972, para a criação da Biblioteca Municipal. Foi possível evidenciar a prestação de serviços públicos, comércio e serviços, capital, informações, transporte, entre outros. Nos anos de 1970, segundo Oliveira e Soares (2002), o número de cidades locais cresceu rapidamente, passando a ter importante papel na rede urbana brasileira. Isso ocorreu em função do advento da modernização e tecnificação. Diante disso, as cidades locais passaram a se especializar para atender a determinados tipos de produção que se encontravam desenvolvidas no seu entorno rural.

O levantamento de documentos referente ao município de Monte Alegre de Minas, nos anos de 1970, revelou indícios de que a cidade se encontrava em "desenvolvimento". Cabe refletir se essas benfeitorias atendiam a toda a população. Verificamos que os benefícios se limitavam à área urbana, atendendo, apenas, 5.700 habitantes, sendo que, no total, a 
população monte alegrense corresponderia a 14.687. As leis que existiam para beneficiar o perímetro rural eram referentes à compra de maquinários.

\section{A educação rural em Monte Alegre de Minas}

De acordo com o artigo $1^{0}$, da Lei 5.692, de 11 de agosto de 1971 , o ensino de $1^{0}$ e $2^{0}$ graus tinha por objetivo geral proporcionar ao educando a formação necessária ao desenvolvimento de suas potencialidades, como elemento de autorrealização, qualificação para o trabalho e preparo para o exercício consciente da cidadania. De acordo com Silva Júnior (2007), com a criação da Reforma Educacional de 1971, no período da Ditadura Militar, espalharam-se escolas municipais rurais no estado mineiro. Esse fato não foi diferente no município de Monte Alegre de Minas, pois evidenciamos a existência 38 escolas rurais, espalhadas no município, nesse contexto.

O tipo de construção das escolas era de alvenaria, a média de área construída correspondia a $35 \mathrm{~m}^{2}$, geralmente, uma sala de aula e cozinha. Essas escolas foram denominadas de escolas isoladas. A análise dos documentos nos permite concordar com Flores (2000), ao argumentar que esse tipo de escola significou economia de dinheiro público, a que acontecia por meio da exploração do trabalho do professor, que, além de mal remunerado, assumia a função de docente, faxineiro, diretor, coordenador, cozinheiro e secretário. As escolas rurais de Monte Alegre assemelhavam-se às escolas rurais localizadas nas diversas partes do Brasil: salas multisseriadas, número reduzido de alunos, difícil acesso tanto para professores, quanto para os estudantes, professores não qualificados, inexistência de condições físicas e de pessoal que garantissem um funcionamento razoável das escolas.

Outra característica que marcou a educação rural, nos anos de 1970, foi a diminuição do número de alunos. Essa questão pode ser entendida como reflexo da modernização conservadora que houve no campo, e, consequentemente, a expulsão do trabalhador rural, que se via obrigado a migrar-se para o meio urbano.

Com o intuito de aprofundar as reflexões sobre a educação rural em Monte Alegre de Minas, nos anos de 1970, detivemo-nos na Escola Municipal Olímpio de Vasconcelos, por termos tido acesso ao um número maior de documentos, tais como: boletins de alunos; histórico escolar; quadro escolar do ano de 1971; folha de registro geral da classe; folha de frequência mensal; relatório de atividades; ata do resultado final; registro de matrícula; registro de frequência diária; folha de lançamento bimestral; anexos; pedido de exoneração, caracterização da escola. 


\section{A Escola Municipal Rural Olímpio Vasconcelos}

A Escola Municipal Olímpio Vasconcelos, localizada na fazenda Buriti, na região do Garcias, de acordo com o documento de caracterização da escola, de 1971, passou a ser mantida pela Prefeitura Municipal de Monte de Alegre de Minas, a partir da construção do “novo" prédio, em 06/11/1966. A área construída da escola consistia em $48 \mathrm{~m}^{2}$ de alvenaria. A água era obtida por meio de uma cisterna. Nesse cenário, funcionava em dois turnos manhã (7horas às 11:30 min.) e vespertino (12:00 às 16:30), sendo que, a partir do ano do ano de 1977, esta escola passou a funcionar apenas em um período, vespertino (11:00 as 16:00). Nos anos de 1970, atuavam duas professoras em dois turnos e estudavam 58 alunos.

De acordo com o documento de caracterização da escola, de 1977, a escola contava com o seguinte mobiliário: 22 carteiras, 2 quadros-negros, 1 cadeira, 1 filtro de água. Em outro documento referente à parte física, desse mesmo ano, registra um atestado com a seguinte informação: a água utilizada por esta escola é potável, com condições de ser aproveitada para ser filtrada.

A análise da infraestrutura revela o descaso com a educação no meio rural, marca dos anos de 1970 e que ainda pode ser observada nos dias atuais. Permite-nos concordar com Bezerra Neto (2009), quando assegura:

As diferenças entre a educação dos filhos dos trabalhadores rurais e do homem citadino ampliam-se ainda mais quando consideramos a infraestrutura disponibilizada para ambos, visto que as escolas rurais são submetidas a situações bem mais precárias (p.1).

A precariedade do espaço escolar, também pôde ser evidenciada em relação aos materiais didáticos utilizados, ao mobiliário da sala de aula e ao lanche oferecido aos alunos, dados que confirmam a ausência de investimento na educação rural no município. Tais questões foram registradas em diferentes trabalhos realizados em outros municípios brasileiros, como, por exemplo, Silva Júnior (2007) e Flores (2000). Sobre este assunto, registramos o que disse a professora Maria Aparecida, que atuou, ao longo dos anos de 1970, na escola Olímpio Vasconcelos:

Não tínhamos material para dar aula para os alunos. Era muito difícil. Para realizar o trabalho, tínhamos que enfrentar muitos desafios. Além da falta de material, não tínhamos conforto na sala, era tudo muito precário, faltava até alimento para as crianças (Professora Maria Aparecida, 2013). 
Continuamos nossa análise, apresentando, por meio do estudo dos documentos, quem eram os alunos da escola. Os pais dos alunos eram lavradores e as mães donas de casa. No ano de 1971, encontramos o registro de um aluno que era filho de uma professora, e muitos filhos de pais analfabetos e outros pais, que tinham alguma escolaridade, mas não ultrapassavam os anos iniciais do ensino fundamental.

A sequência documental do Registro de Matricula revela que essa escola recebia alguns alunos migrantes, com maior ênfase, nos anos de 1971 e 1977. Em 1971, havia 2 estudantes vindos do estado de Goiás e 2 alunos do Rio Grande do Norte. Em 1977, um aluno de Alagoas e um da cidade vizinha Centralina. A média de alunos matriculados na escola era de 53 estudantes, dessa forma, podemos constatar que o número de alunos vindos de outras regiões, não era tão expressivo.

Quanto à idade escolar, os documentos revelam a defasagem idade/série, além do abandono ou transferência. Ao analisar os históricos escolares, identificamos que 5 alunos, que iniciaram seus estudos na década de 1960, estavam concluindo a quarta série no ano de 1975. O tempo que eles levaram para finalizar a quarta série foi de 6 a 10 anos. Podemos levantar algumas hipóteses a respeito desses sujeitos, uma delas é que abandonaram a escola, para acompanhar os pais, pois, conforme Silva Júnior (2007), é frequente a rotatividade do trabalho no meio rural. Na E.M.R. Olímpio Vasconcelos, era comum os alunos não finalizarem o ano letivo por motivo de transferência. E a professora Maria Aparecida (Lila) nos relata este fato em uma entrevista. Ao questioná-la se os alunos concluíam os estudos, ela nos respondeu:

Concluíam! concluiam ! Mas era comum o prolongamento do tempo escolar, porque eles mudavam muito, acompanhavam os pais, e era comum mudar de fazenda procurando um emprego melhor. Outra coisa que era comum, era a ausência das crianças no período de colheitas, como também no período das chuvas. (Maria Aparecida, 2013).

Por meio da narrativa da professora Maria Aparecida, percebemos que se aproxima da afirmação de Silva Júnior (2007), pois ambos destacam que os pais estavam sempre buscando melhores condições de emprego. Os números registrados pela documentação consultada nos revelam grande quantidade de transferências e admissões de alunos, o que confirma a rotatividade.

Além da narrativa da professora, os documentos demonstraram que, nos primeiros meses do ano letivo, os alunos faltaram menos, porém ao finalizar o ano, evidenciamos um acréscimo nas faltas, o que pode ser explicado pelo fato de, no período de colheitas, os pais 
contarem com o trabalho de seus filhos, e era comum os estudos ficarem relegados a segundo plano.

Ao analisarmos os documentos referentes à escola Olímpio Vasconcelos, consideramos importante buscarmos elementos do currículo e da cultura escolar. Para cumprir este objetivo, retornamos aos documentos que nos proporcionaram vestígios da cultura escolar efetivada nesta escola.

Iniciamos nossas reflexões pelo currículo. As disciplinas ministradas pelas professoras, no início dos anos de 1970, eram as seguintes: ciências sociais, ciências naturais, moral e cívica, matemática, linguagem; no ano de 1973, identificamos as seguintes disciplinas: comunicação e expressão, integração social, matemática, iniciação a ciências. Já no ano de 1975: estudos sociais, comunicação e expressão, ciências. Neste ano se subdividiu em matemática e iniciação á ciência, integração social. Outra mudança observada ocorreu no ano de 1977, quando se tem outras disciplinas, as quais foram subdivididas entre disciplinas avaliadas por conceitos, e outras por notas. As avaliadas por conceitos eram: ensino religioso, educação artística, educação física. E as avaliadas por créditos: comunicação e expressão, integração social, matemática iniciação à ciência.

Podemos compreender o currículo como uma construção cultural, como um modo de organizar uma série de práticas educativas. O conhecimento corporificado no currículo não é algo fixo, mas um artefato social e histórico, sujeito a mudanças e flutuações. Conforme Aplle (1982), o currículo deve ser percebido como um processo constituído de conflitos e lutas entre diferentes tradições e diferentes concepções sociais. A seleção e a organização do conhecimento escolar não podem ser vistas como escolhas inocentes, não são um processo lógico, mas social, no qual convivem, lado a lado, fatores epistemológicos e intelectuais. $\mathrm{O}$ currículo não é constituído de conhecimentos válidos, mas de conhecimentos considerados socialmente válidos. O campo curricular pode ser entendido como um lugar de representação cultural, de avanços e retrocessos, de luta pelo poder, de multiculturas, de exclusão e de escolhas. Nessa óptica, evidenciamos que o currículo trabalhado na escola representava o momento vivido: o período da ditadura civil militar.

Por meio dos documentos, verificamos o desejo de desenvolver hábitos de leitura nos estudantes ou colocá-los em contato com histórias e poesias. Por um lado, observamos poesias relacionadas com o desenvolvimento do patriotismo: Pátria; Ditosa Pátria; Marcha Soldado; dentre outras. Por outro ladro, encontramos propostas de poemas que relacionavam com a vida prática dos alunos, tais como: o ninho; minha enxada; passarinho; tempestade, dentre outras. O que revela a complexidade do espaço escolar. 
No que se refere à prática docente desenvolvida na escola, identificamos, por meio dos relatórios, a descrição de datas comemorativas, sendo que há quatro relatórios para o ano de 1971, e apenas um trata do dias das mães, os outros eram de datas comemorativas: dia 21 de Tiradentes, dia das mães em 9 maio; 25 de agosto dia do soldado; 7 de setembro dia da independência. Descrevemos, a seguir, o relatório de atividades datado em 7 de setembro de 1971:

De acordo com as publicações do calendário cívico social, comemoramos em nossa escola 7 de setembro, semana da Pátria, prestando homenagens a D. Pedro I primeiro imperador do Brasil. Atividades: 1) Palestra feita pela professora com a apresentação de varias ilustrações. 2) Tema Hino a Independência do Brasil de autoria de D. Pedro que as crianças cantaram com muito entusiasmo. 3) Tema: Confecção de um cartaz com a colaboração dos alunos, que foi colocado na parede.

Tema: Leitura feita pelo aluno: Denilson Avelino da Silva, sobre a Independência do Brasil. 5) Tema: auditoria: Cantos e quadrinhos declamadas pelos alunos.

Fazenda Buriti 7 de setembro de 1971. Assinada: Raimunda Justina da Silva' ( Relatório de Atividades, 1971).

De acordo com o relatório, a professora afirma ter realizado, durante uma semana de aula, atividades em função de comemorar a "Semana da Pátria". O documento tem como finalidade registrar as atividades desenvolvidas, e, mais um vez, foi possível evidenciar as características do currículo neste contexto, ou seja, a formação de um cidadão "patriótico".

Ao entrevistar a professora Maria Aparecida, ela nos relatou sobre a exigência de trabalhar com datas cívicas. Segundo a professora, a ordem era que "nenhuma data cívica deveria passar em branco". Também nos narrou que as professoras passavam até a semana trabalhando em função de realizar apresentações para os pais, como, por exemplo, o dia da Pátria.

Em outro relatório, a professora descreve a atividade realizada para comemoração do Dia das Mães:

No dia 9 de maio do corrente ano, na Escola Major Olimpio de Vasconcelos, realizaram-se as comemorações de Dia das mães, com participação de todas as classes e a presença de grande número de visitantes. A festa teve início ás 11 horas e terminou ás 13 horas e $30 \mathrm{~m}$ com temas - $1^{\circ}$ Tema: Dois cantos apresentados pelos alunos em homenagens ás mães presentes e ausentes. $2^{\circ}$ Tema: Distribuição de cartões para as mães dos alunos. $3^{\circ}$ Tema: Apresentação de um grupo de jovens que desfilavam trazendo na frente uma faixa com os dizeres. Para frente Brasil e cantaram em seguida Eu te amo meu Brasil, sendo aplaudidos. $4^{\circ}$ Tema: Apresentação de poesias pelos próprios alunos. $5^{\circ}$ Tema: Palestra pela professora sobre o Dia das Mães, sua origem, etc. $6^{\circ}$ tema - Apresentação de várias duplas, sendo uma composta de dois garotos de 9 anos cada, que cantaram e tocaram cavaquinho com muita graça recebendo aplausos de todos os visitantes. Fazenda Buriti, 9 de maio de 1971. Raimunda Justina da Silva. (Relatório de Atividades, 1971). 
O relatório revela que, mesmo tendo como objetivo comemorar o dia das mães, era reforçada a questão do civismo. Os alunos desfilavam com a faixa com o enunciado "Pra frente Brasil", e a música escolhida para comemorar o dia das mães era utilizada como propaganda da Ditadura Militar.

Outra questão que nos instigou em nossa investigação foi no que se refere à formação de professores que atuavam em escolas rurais. Lembramos que, com o golpe militar de 1964, a educação passou a ser regulamentada pela Lei Federal 5.962 de 1971. Quanto à formação de professores, o artigo 29 enfatizava que deveria ser feita em níveis que se elevassem progressivamente, ajustando-se às diferenças culturais de cada região do país, mas com orientações que atendessem aos objetivos específicos de cada grau, às características de cada disciplina e às fases do desenvolvimento do aluno. O artigo 30 destacava:

Art. 30. Exigir-se-á como formação mínima para o exercício do magistério: a) no ensino de $1^{\circ}$ grau, da $1^{\mathrm{a}}$ à $4^{\mathrm{a}}$ séries, habilitação específica de $2^{\circ}$ grau; b) no ensino de $1^{\circ}$ grau, da $1^{a}$ à $8^{a}$ séries, habilitação específica de grau superior, ao nível de graduação, representada por licenciatura de $1^{\circ}$ grau obtida em curso de curta duração;

c) em todo o ensino de $1^{\circ}$ e $2^{\circ}$ graus, habilitação específica obtida em curso superior de graduação correspondente a licenciatura plena. (BRASIL, 1971, p. 5).

De acordo com Leite (1999), em todos os níveis de escolaridade, o processo escolar foi utilizado como meio de propagação, divulgação e penetração do ideário nacionalistamilitar do Estado. Houve um controle político-ideológico-cultural, principalmente da classe operária, por meio da profissionalização e do currículo escolar mínimo desprovido de um conteúdo crítico-reflexivo. Em relação à formação de professores para a realidade no meio rural, não foi focalizada.

O descaso com a educação no meio rural também foi marca do ensino no município Monte Alegre de Minas, pois a formação das professoras, na grande maioria, não ultrapassava o que, atualmente, denominamos anos iniciais do ensino fundamental. Segundo a professora que atuou na E.M.R. Olímpio Vasconcelos, nos anos de 1970, a formação era precária. Acentuamos em sua narrativa:

Eu estudei até a quinta série só. Não tive como continuar os estudos, pois eu morava na zona rural e não tinha como ficar na cidade para continuar os estudos. Eu fazia o que era possível. Quando tinha algum curso de aperfeiçoamento oferecido pela Secretaria de Educação, eu participava, participei de todos. (Professora Maria Aparecida, 2013). 
Mesmo diante das adversidades, tais como as limitações na formação, trabalho precário, a professora sentiu-se realizada com o trabalho realizado. Ela destaca, principalmente, o reconhecimento por parte dos pais:

Eu era bem vista, era respeitada eu não tenho o que reclamar, os pais gostavam muito da gente. Participavam muito das reuniões e de todas as atividades propostas. Eu achava tudo estava bem, pelos pais eu era muito respeitada. Quanto à prefeitura, era muito difícil, tinha muito atraso no pagamento, e o salário era baixo. Mas, de forma geral, eu fui muito feliz! (Professora Maria Aparecida, 2013).

A narrativa da professora assinala a importância de ser professora e do respeito que tinha em relação aos estudantes e aos pais, mas reforça o descaso do poder público, algo que foi marcante nos anos de 1970 e ainda se mantém nos dias atuais.

\section{Considerações finais}

Ao longo da história da educação brasileira, a educação dos grupos menos favorecidos fora negligenciada pelo Estado e seus mandatários, e pôde-se perceber que no meio rural, isso se manifestava de maneira mais intensa. Como marca de uma educação liberal, mesmo sobre a chancela do signo "para todos", a maior parcela da humanidade esteve, historicamente, à margem do processo educacional, e no Brasil não foi diferente. Conforme nos mostra os estudos de Leite (1999), da população camponesa foi subtraído o direito de acessar o conhecimento produzido historicamente pela humanidade e a ciência de seu tempo. Em determinados momentos da história brasileira, sequer tínhamos instituições públicas de ensino no meio rural e, quando essas instituições eram criadas nesse espaço, resultantes das reivindicações da classe trabalhadora, via-se um arremedo de escola erigida sobre estruturas precárias, financiamentos ínfimos e propostas pedagógicas desconectadas das aspirações e das reais necessidades da população camponesa, bem como distanciadas das condições materiais e objetivas do campo.

Para Cassin \& Botiglieri (2008), a escola rural organizada pelo Estado brasileiro, embora marcada pelo emblema liberal "para todos", convive, em sua natureza, com um paradoxo: na medida em que se busca a materialização da máxima liberal "educação para todos", a escola de caráter universal, imbuída de uma cultura tida como geral, esbarra nas necessidades e especificidades da população camponesa. Esses autores consideram que as 
escolas rurais, ao manifestarem os interesses, a visão de mundo e o modo de vida capitalista, sustentam-se por uma cultura urbano-industrial, que se expressa como única, universal, para todos, e promove assim, a exclusão educacional dos trabalhadores rurais, uma vez que não contemplam as especificidades das relações de sociais de trabalho, das suas condições materiais, do seu modo vida, bem como não valorizam a cultura do povo do campo, seus ideais e valores.

Nosso estudo sobre a educação rural em Monte Alegre de Minas, nos anos de 1970, particularmente, sobre a Escola Municipal Rural Olímpio Vasconcelos, confirmou o descaso com a educação rural no município. Isto ficou evidenciado ao analisarmos os documentos concernentes ao espaço físico e à formação de professores. A narrativa da professora reforça a análise realizada por meio dos documentos. Outra característica da escola, possível de identificar em tantos outros trabalhos que têm como foco a educação rural, diz respeito ao objetivo da escola: ensinar as primeiras letras. Evidenciamos, também, a ideologia veiculada na escola a respeito da ditadura civil militar. Enfim, sintetizamos as características identificadas: precárias condições materiais, baixo investimento; precárias estruturas físicas das instituições de ensino; baixos salários dos professores e precárias condições de trabalho; condições insalubres de trabalho; déficit no quadro de professores; currículos esvaziados de conteúdos.

\section{REFERÊNCIAS BIBLIOGRÁFICAS}

APPLE, Michael W. Ideologia e Currículo. São Paulo: Brasiliense, 1982.

ARROYO, Miguel Gonzalez. CALDART, Roseli Salete. MOLINA, Mônica Castagna (Orgs.) Por uma educação do campo. Petrópolis, RJ: Vozes, 2004.

BENJAMIN, Walter. Experiência e pobreza. In: Magia e técnica, arte política.

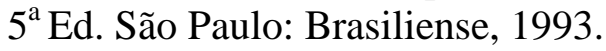

BESSA, Kelly Cristine F. O.; SOARES, Beatriz Ribeiro. Considerações sobre a dinâmica demográfica na região do Triângulo Mineiro/Alto Paranaíba. Caminhos de Geografia Revista On-line. Junho, 2002.

BEZERRA NETO, Luiz. A educação rural no contexto das lutas do MST. In: ALVES, Gilberto Luiz. Educação no Campo: recortes no tempo e no espaço (Org.). Campinas, SP: Autores Associados, 2009.

CARLOS, Ana Fanny. O lugar no/do mundo. São Paulo: FFLCH, 2007.

CASSIN, Marcos; BOTIGLIERI, Mônica Fernanda. "Mundialização, o novo rural brasileiro e a educação". In: LUCENA, Carlos (org.). Trabalho, Precarização e Emancipação Humana. Campinas: Alínea. 2008. 
DUBY, Georges. A História cultural. In: J.P. RIOUX ET J.F. SIRINELLI (Orgs). Por uma história cultural. Lisboa: Editora Estampa, 1998, p. 403-408.

EARP, Fábio Sá; PRADO, Luiz Carlos. O milagre brasileiro: crescimento Acelerado, internacionalização e distribuição de renda 1967-1973. In: FERREIRA, Jorge, e DELGADO, Lucília A.(org.). O Brasil Republicano: o tempo da ditadura. Rio de Janeiro: Civilização Brasileira, 2003.

FLORES, Maria Marta Lopes. Escola Nucleada Rural: Histórico e Perspectivas (Catalão GO, 1998 - 2000) Dissertação (Mestrado em Educação). Faculdade de Educação. Universidade Federal de Uberlândia. Uberlândia, MG, 2000.

GONÇALVES NETO, Wenceslau. Estado e planejamento: A agricultura nos planos de Governo no Brasil (1960-1980). História \& Perspectivas. Nº 10, Jan/Jun. 1994.

LE GOFF, Jacques. História e Memória. Tradução por Bernardo Leitão. -Campinas. Editora da UNICAMP, 2008.

LEITE, Sergio Celani. Escola Rural: urbanização e políticas educacionais . São Paulo. Cortez. 1999.

PORTELLI, Alessandro. História oral como gênero. Projeto História: Revista do Programa de Estudos Pós-Graduação em História PUC-SP, São Paulo: EDUC, 1997.

SILVA JÚNIOR, Astrogildo Fernandes. Saberes e práticas de ensino de História em escolas rurais (um estudo no município de Araguari, MG, Brasil) Dissertação (Mestrado em Educação) . Faculdade de Educação, Universidade Federal de Uberlândia, Uberlândia, MG, 2007.

TOLEDO, Caio Navarro. 1964: O golpe contra as reformas e a democracia. In: REIS, Daniel Aarão, RIDENTI, MOTTA, Rodrigo Patto Sá (Orgs). O golpe e a ditadura militar quarenta anos depois (1964-2004). São Paulo, Edusc, 2004. 